\title{
The slippery slope of nonoperative therapy in early-stage lung cancer
}

\author{
Lara W. Schaheen, MD, and Jonathan D'Cunha, MD, PhD
}

\author{
From the Department of Cardiothoracic Surgery, University of Pittsburgh Medical Center, Pittsburgh, Pa. \\ Disclosures: Authors have nothing to disclose with regard to commercial support. \\ Received for publication May 30, 2017; accepted for publication June 5, 2017; available ahead of print July 18, \\ 2017. \\ Address for reprints: Jonathan D'Cunha, MD, PhD, Department of Cardiothoracic Surgery, University of Pitts- \\ burgh Medical Center, UPMC Presbyterian, Suite C-900, 200 Lothrop St, Pittsburgh, PA 15213 (E-mail: \\ dcunhaj@upmc.edu). \\ J Thorac Cardiovasc Surg 2017;154:1121-2 \\ $0022-5223 / \$ 36.00$ \\ Copyright (C) 2017 by The American Association for Thoracic Surgery \\ http://dx.doi.org/10.1016/j.jtcvs.2017.06.009
}

Although the past decade has witnessed advances in the screening, diagnosis, and staging of lung cancer, our treatment armamentarium remains largely unchanged, consisting of surgery, radiotherapy, chemotherapy, or a combination of these. To date, anatomic resection with lymph node sampling remains the standard of care and principal modality to offer a chance for cure for early-stage non-small cell lung cancer (NSCLC). In patients with poor pulmonary status, the use of lung-preservation techniques such as anatomic segmentectomy has been shown by many investigators to offer promising equivalent outcomes. ${ }^{1,2}$ Yet in patients deemed too high risk or unable to tolerate resection, treatment options have extended into the realm of nonoperative therapies, such as stereotactic body radiotherapy (SBRT).

In the early experience with SBRT, several prospective studies showed the feasibility, safety, and efficacy of SBRT in the treatment of patients with early-stage lung cancer who were deemed inoperable. Investigation into the use of SBRT in the management of patients who were surgical candidates has resulted in a few retrospective single- and multi-institutional studies that have shown both comparable and improved results with SBRT when compared with surgery. Unfortunately, definitive answers and data have not become available because the 3 initial randomized clinical trials comparing SBRT with surgery (Randomized Study to Compare CyberKnife to Surgical Resection in Stage I Non-Small Cell Lung Cancer [STARS trial], Radiosurgery or Surgery for operable Early Lung Cancer Study [ROSEL trial], and American College of Surgeons Oncology Group [ACOSOG] Z4099/Radiation Therapy Oncology Group [RTOG] 1021) were terminated secondary to poor patient accrual. More recently, 2 large cohort studies reported decreased survival with SBRT compared with surgical resection, further muddying the waters. Definitive answers in this area can't come fast enough as the recommendations of CT screening from the National Lung Screening Trial will lead to the detection of more early-stage peripheral tumors. ${ }^{3}$ This same population of surgically resectable patients will likely find themselves in the office of a

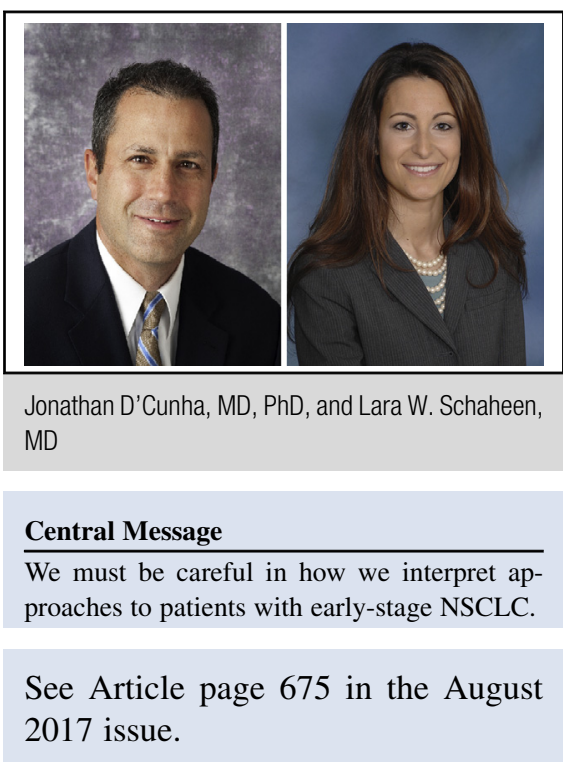

radiation oncologist speaking on the benefits of "zapping" the tumor with SBRT and "avoiding the knife." Unfortunately, our patients aren't fully able to dissect the literature and the nuances of the trials.

Yerokun and colleagues ${ }^{4}$ used the National Cancer Database to examine the overall survival of patients who received SBRT versus a wedge resection in the treatment of clinical T1N0 NSCLC. The authors demonstrated that SBRT was associated with significantly reduced 5-year survival compared with wedge resection after adjustment for covariates. In a subgroup analysis, the authors demonstrated a survival benefit in patients undergoing wedge resection who were aged more than 80 years and patients with multiple comorbidities.

Yet we cannot forget the important benefit surgical therapy provides beyond just removal of the tumor. Surgery affords accurate pathologic staging and guides the need for adjuvant therapy. Cancer and Leukemia Group B (CALGB) 9761 evaluated patients with early-stage lung cancer and the potential impact of micrometastatic disease. ${ }^{5}$ As part of this trial we determined that, overall, only $61.7 \%$ (302 of 489) of patients with suspected stage 1 NSCLC disease retained that stage and diagnosis after complete surgical staging, while $38.3 \%$ had an inaccurate preoperative clinical stage or diagnosis. This change in stage was due to nodal disease. Sobering data in the context of patients evaluated for SBRT who are operative candidates.

In a time of uncertain and changing indications, the careful evaluation by a multidisciplinary team that includes 
experienced thoracic surgeons, radiation oncologists, and medical oncologists, will help guide treatment until definitive data exists. As thoracic surgeons, we are faced with the challenge of adequately comparing the efficacy of these 2 modalities, establishing guidelines for use, and tailoring the treatment to the individual patient in hopes of providing optimal treatment plans for each patient.

\section{References}

1. Chan EG, D'Cunha J. Anatomic segmentectomy for lung cancer: can we believe the hype? Transl Lung Cancer Res. 2015;4:220-2.
2. Whitson BA, Groth SS, Andrade RS, Maddaus MA, Habermann EB, D'Cunha J. Survival after lobectomy versus segmentectomy for stage I nonsmall cell lung cancer: a population-based analysis. Ann Thorac Surg. 2011; 92:1943-50.

3. Whitson BA, D'Cunha J. The National Lung Cancer Screening Trial: the ripple effect begins? Semin Thorac Cardiovasc Surg. 2010;22:274-5.

4. Yerokun BA, Yang C-FJ, Gulack BC, Li X, Mulvihill MS, Gu L, et al. A national analysis of wedge resection versus stereotactic body radiation therapy for stage IA non-small cell lung cancer. J Thorac Cardiovasc Surg. 2017;154:675-86.

5. D'Cunha J, Herndon JE II, Herzan DL, Patterson GA, Kohman LJ, Harpole DH, et al. For the Cancer and Leukemia Group B: poor correlation between clinical and pathological staging in stage I non-small cell lung cancer: results from Cancer and Leukemia Group B 9761, a prospective trial. Lung Cancer. 2005;48:241-6. 